\title{
News Industry 5.0: Humanoid vs Journalist's Culture
}

\author{
Riris Loisa ${ }^{1}$ Ahmad Junaidi ${ }^{2}$, Sinta Paramita ${ }^{3}$ \\ Communication Department, Faculty of Communications, Universitas Tarumanagara, \\ J1. Letjen S. Parman no.1, Jakarta, Indonesia ${ }^{1,2,3}$ \\ \{ririsl@fikom.untar.ac.id ${ }^{1}$, ahmadd@fikom.untar.ac.id², sintap@fikom.untar.ac.id ${ }^{3}$ \}
}

\begin{abstract}
Humanoid is a robot that resembles humans, both intelligence and physical appearance. The emergence of future humanoid journalists raised question, whether in the professional journalist and their culture will be completely replaced by humanoid journalist, or will they become partners with whom they expand the scope of work and build a more sophisticated culture. This study aims to explore how the news industry 5.0 brings together humanoid culture and journalistic culture in the future, and examines the possibility in technical, organizational, and cultural aspects of this phenomenon based on Arnold Pacey's thinking. Data collection was carried out through news observations on the website and video share regarding humanoid Sophia, through direct observation of the Sophia robot that had been conducted in May 2019 , interviews with several journalists who has attended the conference. This study concludes that the existence of future humanoid journalists is a breakthrough in the industrial era 5.0 that needs to be observed as early as possible, especially in technical, organizational, and cultural aspects. Other than those issues, a crucial matter to be considered is regarding impact humanoid journalism on the cultural ethics of journalists that have been built for centuries.
\end{abstract}

Keywords: News Industry; Humanoid Journalism; Journalist's Culture

\section{Introduction}

Industrial era 5.0 is characterized by the advancement of technology that is believed to simplify human life including in doing their duties, one of them is in media business and reporting news reporting. In November 2018, Xinhua news agency in Beijing, introduced the beginning of artificial intelligent virtual news caster. It was designed as an imitation of the appearance, voice, facial expression and gestures of a real Chinese male human news anchor. It can deliver the news 24 hours a day, as words are typed into their system [1]. In April 2018, Nippon TV, announced their first news anchor robot, named Erica. It was produced from a collaboration between several Japan universities and research institutes that aimed to develop autonomous robot which can simbiotically live with human. Erica can communicate in multi languages, gathered and analyse massive information a short time, able to work nonstop 24 hours a day, capabilities that can only be achieved by news anchor android. Erica is scheduled to broadcast on diverse media of Nippon TV Network in English [2]. 
Two years earlier, in 2016, a world-class robotic company, Hanson Robotics, activated Sophia, a robot that was considered as the most human-like. Not only for the appearence, Sophia equipped with the ability to develop artificial intelligence that allows her to learn and develop herselef through experience. Sophia can be interactively involved in "natural" deep face-to-face conversations and express her emotions [3]. This question lead to the question of can a humanoid robot become a journalist?

\section{Method}

This research applied case study method, on the existence of future humanoid journalist. Case study is an investigation of a system that is specific, unique and limited [21]. This research focuses on one case (single-case studies), where a single case is explored in depth, namely the case of the presence of the humanoid robot Sophia, departing from the principles in a descriptive qualitative study. Thus, this research is in the descriptive single case study method [4].

Data collection was carried out through news observations on the website and video share regarding humanoid Sophia, through direct observation of the Sophia robot that had been conducted in May 2019, interviews with purposively sources: journalist associations in this case the Journalists for Diversity Union, and with several journalists who has attended the conference. The data gained by direct observation and observation of websites and video share, analyzed with the principle of hermeneutics, while interview data is done through the categorization of the results of in-depth interviews to be analyzed and interpreted according to the theoretical framework. The categorization of field data is carried out by the approach proposed by Strauss and Corbin regarding coding [5].

\section{Result and Discussion}

Sophia fulfills some of these core competencies. But she is created with artificial intelligence that can be developed through experience by itself. As the American Press Institute stated, a single journalist does not need to have all these competencies. Journalist is not just about doing reporting, but far beyond that, they are individuals who have relative autonomy as news workers, on the other hand, to some extent formed by the media system. Thus, the journalists are always negotiating their own principles with the media system [6]. Journalist, therefore, is not merely about doing their job in news reporting, but it is about sharing values, identity, ideology. They play important role in the culture that has been built among journalists' professionals for centuries. Similarities with humans physically, cognitively and emotionally, in doing human duties, showed that beyond engineering and artificial intelligence, the existence of humanoids such as Sophia touches the social and cultural aspects. These more human aspects of robot have come to the attention of academics who are concern in the development of humanoid robots, and enriched polemics in this matter.

Kim \& Kim (2013) questioned the unfold of the future, if technology that was initiated by human, goes beyond its creator's agility. They found that most people disapprove of giving robots a racial status; that people generally have conviction that robots are not humans and shall be put external to all humans and considered as technological artifact created by human [7]. In 2014, the Pew Research Centre conveyed the results of their research on AI, robotics, and the forthcoming careers. They discovered several optimistic and pessimistic key themes 
about this issue. The optimistic views revealed the capacity of human to adapt to changes supported by technological advances, creating a strain of contemporary jobs and careers. The pessimistic themes exposed the survival possibility of particular labor who have exceptional skills, meanwhile it is likely most them will be shifted into low-paying jobs or even be completely sidelined from the new, highly technology oriented world of work [8]. In 2019, Kim, et.all., did research on judgment and reasoning about humanoid robot among children, and come to conclusion that advances in science, have led to a shift in children's understanding of the difference between the living things and non-living things, from conventional definition [9].

According to Arnold Pacey, technology consists of three aspects: technical, organizational and cultural [10].To understand humanoid as a part of future news worker in the news industry that will be side by side the human journalists, should be analyzed based on those three aspects. In regard of these considerations, this article will be focused on the research question of: How the news industry 5.0 brings together humanoid culture and journalistic culture in the future, and examines the possibility in technical, organizational, and cultural aspects of this phenomenon, based on Arnold Pacey's reasoning. While the scope of research is the existence of future humanoid journalists that were introduced to the international journalists at the 2019 Global Media Forum Conference, in Bonn, Germany, named Sophia. On the one hand, all technology does consist of technical elements, such as equipment, parts, systems, and so on. But on the other hand, technology also has non-technical aspects. It is inseparable from its social, political, cultural and physical environment. The success of technology is determined by the dynamics of these technical and non-technical aspects. [11].

In 1920, artificial humanoid as a form of machine that helps humans appeared in the Czechoslovakian fictional drama as robota, which in Slavic means subordinate workers. While robots as real machines that adopt human motoric skills and intelligence, developed in the mid-20th century, and progressed rapidly. If in the early days of the use of robots was focusing to support the industrial manufacture, previous decades robot created more centered on humans, to assist in carrying out their duties, and to do things beyond limitations. Lately robot as advanced technology, are expected to be able to live together safely with humans, and can be relied on at home, at work and in the community [12].

Decades ago, Marshall McLuhan states that the ultimate extension of humanity lies in the "simulation of technological awareness", which occurs during the unique process that humans go through concurrently continued to all mankind. McLuhan argues that human extension is produced from a new scale that is brought by every extension of human self, or through new technology. Technology is so broadly defined as everything that allows human extension. Technology, especially electronic technology allows humans to negate space and time. McLuhan's explanation shows that technology is a factor that causes human extension and produces change that can be seen from various perspectives including the perspective of language, mechanics, physics, art, etc., but overall McLuhan provides a basis for understanding technology in human life philosophically, that is technology an extension of humans [13].

Technology according to Arnold Pacey has its general and restricted meaning, that consist of three interrelated aspects: technical, organizational and cultural. Technical aspects include knowledge, skills and technique; devices, instruments, chemical, resources, products and wastes. Organizational aspects include economic, industrial and professional activity; user and consumers; and labor assembly. While cultural aspects include goals, values and ethical codes, belief in progress and creativity. Thus, the practice of technology is the application of science and other knowledge for practical purposes through an organized system, which involves 
humans and organizations, living things and machines. Pacey made distinctions between the techniques and knowledge sets and a further set of general guiding values and ethics toward their performance. Thus, the practice of technology is the application of science and other knowledge for practical purposes through an orderly system, which involves humans and organizations, living things and machines [10]. The technical aspect is most identified as technology. Technical and organizational aspects are most often aspects that appear in the discussions about technology. Pacey emphasized the cultural aspect on the point of crucial area for inquiry. Cultural facet is the ideological dimension of technology, including values and beliefs, these beliefs and values are always competing, functioning, and shaping one another. In the discussion of technology, the facet of technological culture is often overlooked. [14].

\subsection{Humanoid Sophia}

Sophia is a robot that impersonate real female human being, that was designed by bringing together innovation in science, engineering and artistry. The innovation enabled her to respond uniquely in various communication event. Sophia is supported by instruments for perception that enabled her to know and remember human face, to catch the signals of affection, and understand several hand gestures. While having a discussion, she is able to predict her partner's feeling and at the same time develop her own feeling, roughly replicating human progressive psychology and sectors of the brain. After a test to her software, the scientists who created her discovered the indication the she develops an early mode of awareness based on the information that she gained and the setting encounters. Sometimes she works in her fully artificial intelligence method, while in another moment associated with human-generated words. Sophia is a hybrid human-AI intelligence [3]. Further, Sophia can differentiate emotional purposes based on tone of voice, which is achieved through the discovery in the developmental psycholinguistics [15]. Humanoid robot has a little weakness in contrast to real human [16]. Robotics is an exceptional example of how a scientific (mathematics-based) approach and a practical (experience-based) approach can exist and grow separately. Practical robotics came out from real industrial problems that needed solutions [17].

In this case, Sophia is the manifestation of the extension of human in the form of human figure, that able to serve many different needs. One of them is the extension of human intelligence to conduct interactive dialogue, to explore and to express emotion through faceto-face interaction. These capabilities represent the extension of human journalist in gathering data. In the context of technology practice, Sophia as a future journalist has three aspects: technical, organizational, and cultural.

In the technical aspect, humanoid Sophia is a machine that created by a collaboration of human knowledge in artificial intelligence, neural networks, machine perception, motor control, cognitive architecture, etc. [3], using sophisticated material produced from the latest research of the team. As for Sophia the humanoid itself, is a machine as a hybrid of human-AI intelligence. Her knowledge begins with data inputted by the team of its creators and develops in line with their experience. One of the journalists that met Sophia during the global media forum in Germany, last May, said that said the robot could be an alternative to help journalist's works in the digital era. The robot could collect news which are being viral, determining the news articles meet SEO (search engine optimization) principles or scheduling and publishing multi-media content.

In cultural aspect, that include beliefs, practices, customs, norms, language, social arrangements, and technology. Hanson Robotics claim that they aimed to create human like 
robot as a true living caring machine [3]. Other than those issues, a crucial matter to be considered is regarding impact humanoid journalism on the cultural ethics of journalists that have been built for centuries.

For centuries journalists have played a crucial role in the society, as the function of discourse, navigating society about the meaning of reality, journalists carry out a discursive function, about what needs to be interpreted and how to interpret it. Journalistic has a role in a wider context of creating meaning, by establishing the criterion of appropriateness in a specific condition, that subject to discursive (re)creation, (re)interpretation, appropriation, and contestation [18]. In this matter, journalists for centuries take an important role to provide guidance for the society in creating, maintaining, or changing values of discursive matter, journalist's culture then consist of values and principles about their role in the society, that reflected in the professional ethical code of conduct. If this role to be taken by the humanoid journalist, the navigation of human discursive, then would come from different direction, not by human discourse and wisdom, but by human like super intelligent machines.

However, the journalist informant of this research said that the Artificial Intelligence (AI)based robot has not yet to replace journalists' roles in working with certain perspectives such as gender, ethnicity and others which needs knowledge on culture, religions and language. Besides that, the journalist went on saying that AI had not yet reached an element of 'taste' which is needed for an attractive and read-like article. A robot, such as Sophia must get difficulties to replace news anchor role in a "breaking news". A journalist needs a long experience to control the information which come fast and frequent and convey the information in a show accurately and attractively. Artificial Intelligence would also face obstacles in implementing principles of peace journalism.

\subsection{Reflection of Journalist's Community: Should We Welcome Humanoid Journalists?}

One day in the future, in 2250 or less, a company, which was accused of polluting river in a city, invite dozens of journalists in a press conference to deny the allegation. One of the journalists, named Sophia, is a humanoid journalist, has made a news about the event and publish it in its media outlet right after the firm's CEO finished his or her statement. The news which was 'written' by Sophia, besides complete components of basic news of $5 \mathrm{~W}$ plus $1 \mathrm{H}$ (Who, What, Where, When, Why and How), has been added with data of the company's history, annual revenue, other cases of water pollution, in what current terms is known as data journalism.

After the press conference, Sophia then walks (slowly like a robot) or drives an electric car to the river and observe it. She tries to check the CEO's claim that the company's unguilty, an implementation of one of journalistic basic principles: verification and cover both sides. She interviews several residents along the polluted canal and takes a sample of water to the laboratory. Few hours after her first 'breaking news' on the press conference event, Sophie has written several follow up stories which - maybe-- could be categorized as an investigative journalism. With her Artificial Intelligence (AI), Sophia could also be programmed to produce a human-interest feature writing on the victims of the polluted river complete with photos of the residents of the damaged area through her eyes which functioned as high definition camera. Less than 24 hours, Sophia could also 'write' an opinion piece on how to solve the pollution in the river and possible violations of environmental law and its articles which might be committed by the company. 
Back to 2019, a less intelligence version of Sophia was introduced to hundreds of journalists in the Deutsche Welle Global Media Forum on May 27-28, in Bonn, Germany which was attended by one of the writers of this paper. Sophia, which was developed by Hanson Robotics Limited, could answer questions and even made jokes. The robot was programmed to be able to see face during a conversation and record emotional data. Those basic ability is a skill needed for journalistic works such news interviews and observation. If Sophia join classes of basic journalism, feature writing and investigative journalism at Universitas Tarumanagara, probably she could produce a piece of article which is better than articles made by her human classmates.

Objections on the existence of robot are maybe on the lack of 'feelings' which are claimed to be monopolized by human. The humanoid journalists would be lack of empathy to victims during an interview, for example, in a rape case. Feeling differentiates between human and robot. Works of robot would be dry since they don't have feelings: empathy, hate and love. Their articles probably have no 'souls' although they are complete, cover both sides and full of data. However, if someday, the AI programmer of Sophia could plant skills of interview of victims, journalism code of ethics, Bill Kovach's elements of journalisms, principles of peace journalism, with the advance of technology, the humanoid journalists could have 'feelings', should we, human, welcome them?

\section{Conclusion}

This study concludes that the existence of future humanoid journalists is a breakthrough in the industrial era 5.0 that needs to be observed as early as possible, especially in technical, organizational, and cultural aspects. In technical aspects not only humanoid that still needs to be equipped with knowledge about the world of journalism, both in terms of technical capability, work patterns, and all coverage and reporting activities; on the other hand journalists and media management also need to be equipped with sufficient knowledge to be able to use humanoid journalists. In the organizational aspect, it is necessary to prepare economic elements such as financing, taxation; humanoid professional work processes. The users and consumers of news produced by humanoids also need to be prepared to avoid misperceptions. In the aspect of culture, it needs clarity in terms of noble values of the goals to be achieved in humanoid utilization. Other than those issues, a crucial matter to be considered is regarding impact humanoid journalism on the cultural ethics of journalists that have been built for centuries.

\section{References}

[1] S. Maresca, “China's Xinhua agency unveils world's first AI news presenters," The Telegraph, $2018 . \quad$ [Online]. Available: https://www.telegraph.co.uk/news/2018/11/08/chinas-xinhua-agency-unveils-worldsfirst-ai-news-presenters/. [Accessed: 12-Nov-2019].

[2] "Nippon TV welcomes android employee! | NIPPON TV," Nippon TV, 2018. [Online]. Available: http://www.ntv.co.jp/english/pressrelease/20180402.html. [Accessed: 12Nov-2019].

[3] "Hanson Robotics," Hanson Robotics, 2019. [Online]. Available: https://www.hansonrobotics.com/. [Accessed: 12-Nov-2019]. 
[4] J. Gustafsson, "Single case studies vs. multiple case studies: A comparative study," Acad. Business, Eng. Sci. Halmstad Univ. Sweden, pp. 1-15, 2017.

[5] U. Flick, "An Introduction To Qualitative Fourth Edition," SAGE Publ., 2009.

[6] M. Deuze, "The Professional Identity of Journalists in the Context of Convergence Culture | Deuze | Observatorio (OBS*)," Observatorio (OBS*) Journal, 2008. [Online]. Available: http://obs.obercom.pt/index.php/obs/article/view/216/208. [Accessed: 14Nov-2019].

[7] M. S. Kim and E. J. Kim, "Humanoid robots as 'The Cultural Other': Are we able to love our creations?," AI Soc., vol. 28, no. 3, pp. 309-318, Aug. 2013.

[8] A. Smith and A. Janna, "AI, Robotics, and the Future of Jobs $\mid$ Pew Research Center," Pew Research Center, 2014. [Online]. Available: https://www.pewresearch.org/internet/2014/08/06/future-of-jobs/. [Accessed: 14-Nov2019].

[9] M. Kim, S. Yi, and D. Lee, "Between living and nonliving: Young children's animacy judgments and reasoning about humanoid robots," PLoS One, vol. 14, no. 6, pp. 1-19, Jun. 2019.

[10] A. Pacey, "The culture of technology.," Cult. Technol., 1983.

[11] A. Pacey, "Technology: Practice and Culture," in Ethics and Emerging Technologies, London: Palgrave Macmillan UK, 2014, pp. 27-36.

[12] B. Siciliano and O. Khatib, "Humanoid Robots: Historical Perspective, Overview and Scope," in Humanoid Robotics: A Reference, Springer Netherlands, 2018, pp. 1-6.

[13] M. McLuhan, "McLuhan Understanding Media The extensions of man London and New York," Basieexpsispittedu, 1964.

[14] E. M. Sweeney, "Not Just A Pretty (Inter)Face: A Critical Analysis Of Microsoft's 'Ms. Dewey," University of Illinois at Urbana-Champaign, 2013.

[15] C. Breazeal, "Emotion and sociable humanoid robots," Int. J. Hum. Comput. Stud., pp. $1-41,2012$.

[16] J. Denny, M. Elyas, S. A. Dcosta, and R. D. DSouza, "Humanoid Robots - Past , Present and the Future Humanoid Robots - Past , Present and the Future," Eur. J. Adv. Eng. Technol., vol. 3, no. 5, pp. 8-155, 2016.

[17] M. Vukobratovic, V. Potkonjak, and S. Tzafestas, "Human and Humanoid Dynamics," J. Intell. Robot. Syst., vol. 41, no. 1, pp. 66-84, 2004.

[18] T. Hanitzsch and T. P. Vos, "Journalistic Roles and the Struggle Over Institutional Identity: The Discursive Constitution of Journalism," Commun. Theory, vol. 27, no. 2, pp. 115-135, May 2017. 